\title{
Las reformas procesales penales en Colombia
}

GLORIA LUCÍA BERNAL ACEVEDO*

\section{RESUMEN}

Colombia no ha sido ajena a los cambios legislativos de índole procesal; precisamente en este campo se han registrado cambios radicales entre el procedimiento anterior y el posterior a la Constitución de 1991. Antes de la Constitución de 1991, nuestro país contó con un procedimiento penal mixto que tenía una clara tendencia inquisitiva al centralizar las funciones de acusación y juzgamiento en un mismo funcionario: el juez de la causa. Igualmente en la fase de instrucción predominaba la forma escrita; y en el juzgamiento, la oral. Con la creación de la Fiscalía General de la Nación, en 1991, la legislación procesal buscó en el sistema mixto una tendencia acusatoria real, al otorgar la función de investigar a un estamento diferente a los jueces. La Ley 600 de 2000 es un sistema procesal mixto con rezagos inquisitivos, pero con una marcada tendencia acusatoria. La Ley 906 de 2004 establece en Colombia una legislación penal acusatoria que empezó a regir a partir del 2005 y que pretende un código fuerte en su acusación, con posibilidades de defensa en la contradicción, con la participación del Ministerio Público en interés de la sociedad, recuperando la categoría cultural del juez.

\section{PALABRAS CLAVE}

Sistema procesal mixto, legislación penal acusatoria. 


\section{ABSTRACT}

Colombia has not been distant to the legislative changes of legal type,and exactly in them, some radical changes between the existing procedure before the Constitution of 1991 and the procedure after have been registered. Before the Constitution of 1991 our Country counted on a mixed penal procedure that had a clear inquisitive tendency by centralizing the accusation and judgement functions in one official: The Judge of the Case . Equally it prevailed the written form in the investigation phase and the oral form in the judgement phase. In 1991 it is created the National Office of the Public Prosecutor, the Legal legislation searched in the mixed system a real accusatory tendency, by giving the investigation function to a estate different of the judges.The 600 Law of 2000 is a mixed trial system with inquisitive remainders but with a marked accusatory tendency.The 906 law of 2004 establishes in Colombia an accusatory penal legislation, beginning 2005, that pretends a Code strong in its accusation, with defense possibilities in the contradiction, with the participation of the Attorney General in interest of the Society and in which the cultural position of the Judge is recovered.

\section{INDEX TERMS}

Accusatory penal legislation, mixed trial system.

\section{INTRODUCCIÓN}

El desarrollo de este trabajo tendrá como marco de referencia la Constitución Nacional de 1991. De esta manera, se relacionarán las tendencias existentes en la legislación procesal penal antes de la Constitución y las promulgadas con posterioridad, teniendo en cuenta la legislación vigente en algunas partes del país hasta el 2008, así como la que comenzó a regir en Bogotá y el Eje $\mathrm{C}$ afetero a partir del 1 de enero de 2005.

Los cambios legislativos en cualquier país obedecen a la política criminal que perfila y moldea el procedimiento en la investigación y juzgamiento, conforme a un matiz político-social. Así, por ejemplo, si el Estado tiene una orientación autoritaria prevalecerá la tendencia inquisitiva; por el contrario, si posee una tendencia democrática, están al orden del día los procedimientos acusatorios. No se puede afirmar, con todo, que exista en la actualidad un sistema absolutamente puro.

Las características fundamentales de uno y otro sistema nos servirán de prisma del análisis. En el sistema inquisitivo, las funciones de acusar y juzgar recaen en cabeza de un mismo funcionario. En el sistema acusatorio, dichas funciones están en cabeza de funcionarios diferentes y autónomos. De paso, se puede agregar que el sistema inquisitivo es, por esencia, escrito; el acusatorio, oral. Este prisma permitirá calificar o matizar el sistema mixto procesal penal que ha imperado con posterioridad a la revolución francesa. Colombia no ha sido ajena a los cambios legislativos de índole procesal, y ha registrado cambios radicales entre el procedimiento existente antes de la Constitución de 1991 y el procedimiento con posterioridad a ésta. 


\section{NORMATIVIDAD PROCESAL PENAL ANTES DE LA CONSTITUCIÓN DE 1991}

Con el Decreto 409 de 1971 -Código de Procedimiento Penal- adoptado por la Ley 2 de 1982, los jueces de instrucción, creados en el procedimiento penal colombiano desde 1938, no acusaban, ni fallaban, sólo instruían el proceso que se adelantaba contra los presuntos responsables de una ilicitud. Existía dos etapas: sumario y causa. Una vez concluida la etapa instructiva, el juez instructor remitía al juez de conocimiento el expediente para que éste procediera a calificar el mérito del sumario, que podía hacerlo mediante auto de proceder, sobreseimiento temporal o sobreseimiento definitivo. Si el juez de conocimiento acusaba, es decir, si profería auto de proceder, acusaba ante sí mismo, para, una vez realizada la audiencia pública, proferir el fallo. En este sentido, se hablaba de un prejuzgamiento al ser el mismo juez quien formulaba la acusación, juzgaba y fallaba, con fundamento en el veredicto del jurado de conciencia únicamente en casos de homicidio.

Este procedimiento penal mixto tenía una clara tendencia inquisitiva al centralizar las funciones de acusación y juzgamiento en un mismo funcionario: el juez de la causa. Igualmente en la fase de instrucción predominaba la forma escrita; en la de juzgamiento, la oral.

Con la Ley 2 de 1984 se crearon los jueces especializados y se estableció un procedimiento especial para la investigación y juzgamiento de los delitos de secuestro extorsivo, extorsión y terrorismo, centralizando las funciones de investigar y fallar. El sumario se instruía en un término de 30 días; cuando se vencía éste se ordenaba cerrar la investigación y se calificaba el sumario. Ejecutoriado el auto de citación a audiencia, el juez abría el juicio a pruebas por el término de dos días; vencido los cuales, al día siguiente hábil, decretaba la práctica de las pruebas que se practicaban en la diligencia de audiencia pública. Realizada la audiencia, el juez profería sentencia dentro de los cinco días siguientes. La creación de estos jueces especializados se estableció por un término de seis años.

Con el Decreto 50 de 1987, se pretendió un tímido tránsito de un sistema procesal inquisitivo en la instrucción hacia un sistema acusatorio en la etapa de la causa. Para ello, se le otorgaron funciones a los jueces de instrucción criminal para que, una vez concluida la investigación, procedieran a calificar el sumario por medio de una resolución acusatoria, preclusiva o de reapertura de la instrucción, según el caso. En el evento de proferirse resolución acusatoria, debería remitirse el expediente al juez de la causa, perdiendo toda competencia. Es decir, el juez instructor acusaba por medio del auto interlocutorio que calificaba el mérito del sumario, pero no era sujeto procesal en la etapa del juicio.

El artículo 467 del mencionado Decreto consagraba los funcionarios competentes para calificar. En los procesos por los delitos de competencia de la Corte Suprema de Justicia, de los tribunales superiores y de los juzgados municipales, el mérito del sumario era calificado por la corporación o juez municipal correspondiente. En los procesos por delitos de competencia de los jueces del circuito y superiores, el mérito del sumario lo calificaba el juez de instrucción criminal.

Igualmente, esta legislación establecía un procedimiento abreviado en casos de captura del imputado en flagrancia o cuando existiese confesión simple. Una vez indagado y resuelta su situación jurídica, en el mismo auto el juez ordenaba las pruebas que debían practicarse en audiencia pública. Realizada ésta, se procedía a 
fallar. Cuando la competencia era atribuida a un juez superior o del circuito, el juez de instrucción criminal, al proferir la medida de aseguramiento, enviaba el expediente al respectivo juez, solicitándole citación a audiencia. El juez de conocimiento se sometía a idéntico procedimiento. Dicho procedimiento no se aplicaba cuando el delito era de competencia de los jueces superiores con intervención de jurado (homicidio, rebelión o sedición y los conexos con éstos) o se trataba de inimputable.

Con posterioridad, se presentaron modificaciones legislativas que eliminaron el jurado de conciencia; en un momento dado, se trató de establecer un jurado de derecho, pero éste no prosperó. El procedimiento en la fase de instrucción era absolutamente reservado a las partes; en la preliminar, era secreto antes de la versión libre del imputado. La detención preventiva del sindicado era la regla general.

Si bien se consagraba como medidas de aseguramiento la conminación, la caución y la detención, la detención era la predominante, pues procedía no sólo en delitos que tuvieran prevista pena de prisión cuyo mínimo fuese o excediera dos años, sino que, además, se fijaba una lista taxativa de 30 delitos más en los que aquella procedía, así la pena fuera de arresto.

La indagación preliminar, en caso de duda sobre la procedencia de la apertura de la investigación, era reservada. Así lo establecía el artículo 343: "Las diligencias de indagación preliminar son reservadas, pero posesionado legalmente el defensor, podrá conocerlas, cuando se le haya recibido versión al imputado".

Se cambió el sistema de la tarifa legal probatoria por el de la sana crítica. En este sentido, el artículo 253 establecía que las prueban debían ser apreciadas en conjunto, de acuerdo con las reglas de la sana crítica.

\section{NORMATIVIDAD PROCESAL PENAL POS- TERIOR A LA CONSTITUCIÓN DE 1991}

En 1991, entra en vigencia una nueva Constitución Nacional, que crea la Fiscalía General de la Nación, la cual conlleva un cambio legislativo mediante el Decreto 2700 de 1991 que entró a regir a partir del 1 de julio de 1992, derogando el Decreto 50, de enero 13 de 1987. Esta legislación pretendió abrir el camino a una tendencia acusatoria real, al otorgar la función de investigar a un organismo diferente a los jueces, como había sido hasta entonces. Así, se diferenciaba claramente la etapa de instrucción a cargo de la Fiscalía y la de juzgamiento en cabeza del juez. En ésta, el funcionario instructor que formulaba la acusación debía hacerse parte dentro del juzgamiento y, por lo tanto, defender su acusación en audiencia pública.

En el Decreto 2700 de 1991, se establecía que el fiscal, una vez había agotada toda la instrucción y, previamente resuelta la situación jurídica con conminación, caución o detención, según el caso, procedía a calificar el mérito sumarial de dos maneras: con resolución de acusación o con preclusión de la instrucción. No se permitía continuar con la instrucción en los casos en que no existiese mérito para acusar o precluir. Esta modificación a los procedimientos tradicionales de investigaciones interminables fue introducida por la Ley 81 de 1993 en su artículo 58. Esta misma Ley otorgó competencia a los jueces regionales para conocer los diferentes delitos establecidos en el Estatuto Nacional de Estupefacientes (Ley 30 de 1986); esta competencia había sido otorgada a los jueces de orden público. En estas condiciones, los jueces de orden público pasaron a convertirse en jueces regionales.

Esta misma normatividad señaló como régimen ordinario de duración de la investigación previa de dos meses si se trataba de delitos comunes y 
de cuatro meses si se trataba de delitos de competencia de los jueces regionales. Como duración de la instrucción se establecían 18 meses, cuando se trataba de uno o dos delitos o sindicados, y 30 meses, si se trataba de tres o más delitos o sindicados. También se estableció el principio de la investigación integral con el cual el funcionario en la investigación de los hechos tiene la obligación de investigar tanto lo favorable como lo desfavorable a los intereses del sindicado y de las demás partes.

El fiscal respectivo, una vez indagado el presunto infractor, resolvería la situación jurídica, ordenando conminación, caución o detención, según el caso. Tratándose de delitos de competencia de la justicia regional, sólo operaba como medida de aseguramiento la detención. En relación con la libertad provisional, ésta operaba en el régimen normal al transcurrir 120 días de privación efectiva de la libertad sin que se hubiere calificado el sumario mediante providencia debidamente ejecutoriada. En los delitos de competencia de los jueces regionales, sólo era viable después de transcurridos 240 días de privación efectiva de la libertad. Si se trataba de tres o más sindicados en el régimen común, operaba la libertad una vez transcurridos 180 días de privación efectiva de la libertad; y en el régimen especial, 360 días. Idéntico resultado se daba en la etapa del juzgamiento pasados seis meses sin que se hubiese celebrado la audiencia pública; en el régimen especial, el término se elevaba a un año.

Ahora bien, en relación con las medidas de aseguramiento, la Ley 81 de 1993, en su artículo 54, estableció el llamado "control de legalidad". Por medio de éste, las medidas de aseguramiento proferidas por el fiscal, una vez ejecutoriadas, podían ser objeto de revisión en cuanto a su legalidad por el correspondiente juez de conocimiento, previa petición motivada del interesado, de su defensor o del Ministerio Público. Si el juez encontrare infundada la solicitud, la desechaba de plano. En caso contrario, la admitía y corría traslado común a los demás sujetos procesales por el término de cinco días, vencido el cual el juez decidía si prosperaba o no. Este control matizaba una tendencia acusatoria aunque no pura, pues en el sistema acusatorio no se permitiría al fiscal tomar medidas que son del resorte eminentemente judicial, como las que afectan la libertad del procesado y de sus bienes.

En el juzgamiento existía un traslado para preparación de la audiencia pública en el que el expediente quedaba a disposición común de los sujetos procesales por 30 días hábiles, para preparar la audiencia pública, solicitar nulidades y pruebas que fuesen conducentes. Correspondía al juez la dirección de la audiencia pública, quien permitiendo la intervención de las partes de acuerdo con un orden legal, el fiscal, representante del Ministerio Público, apoderado de la parte civil, sindicado y defensor. Éstos podían presentar, una vez terminadas sus intervenciones, resúmenes escritos de las razones aducidas y de las peticiones hechas. En la práctica judicial, cuando se tramitaba un proceso sin que el sindicado estuviere privado de la libertad, la audiencia se limitaba a una breve intervención oral en la que se hacía mención a lo que se llevaba por escrito. Así, poco a poco, la audiencia fue perdiendo su esencia de oralidad para dar prelación a los escritos dejados por las partes a disposición del juez.

En el artículo 457 del Decreto 2700 de 1991, se estableció un trámite especial para el juzgamiento de delitos de competencia de los jueces regionales. Esta competencia se estableció por un término de 10 años, contados a partir de la vigencia del Código de Procedimiento Penal, es decir hasta el 1 de julio del 2002, fecha a partir de la cual se pasó la competencia a los jueces del circuito. En este procedimiento, vencido el término de traslado para preparación de la audiencia, el juez, 
dentro de los tres días siguientes, decretaba las pruebas que hubiesen sido solicitadas y las que consideraba necesarias para el esclarecimiento de los hechos. Éstas se practicaban en un término que no podía exceder los 20 días hábiles. Vencido el término probatorio mediante auto de sustanciación que debía notificarse, el proceso se dejaba en secretaría a disposición de los sujetos procesales por el término de ocho días, para que presentaran sus alegatos de conclusión. Dentro de los 10 días hábiles siguientes, el juez dictaba sentencia.

En este procedimiento especial para los delitos de competencia de la justicia regional (secuestro, extorsión...) en la etapa de instrucción se llegó al máximo del sistema inquisitivo, ya que se utilizaron figuras como fiscales "sin rostro", es decir, no era conocida la identidad de los funcionarios instructores por los sujetos procesales. Para ello, en la práctica de las pruebas se hacía a través de oficinas equipadas de todos los mecanismos tecnológicos para no revelar dicha identidad, como micrófonos especiales que distorsionaban su voz. De igual forma, se guardaba la identidad de los testigos mediante un acta de reserva. Hubo situaciones en las cuales no se le permitía a los abogados defensores obtener copias de los expedientes, debiendo éstos utilizar otros mecanismos para recolectar la información procesal, como transcripciones a mano o grabaciones.

En la etapa del juzgamiento (que poseía en el procedimiento ordinario una tendencia acusatoria, aunque en algunos eventos era más formal que real), en el procedimiento especial se consagró un sistema inquisitivo extremo que se extendió de la instrucción a la acusación, eliminando no sólo la posibilidad del debate público, sino, incluso, la de controvertir las pruebas ante el juez que, de paso, también era reservada su identidad. En este procedimiento primaba lo escrito y lo secreto, impidiendo ejercer una defensa técnica. Lo único que se mantuvo como tendencia acusatoria fue mantener que la acusación fuera formulada por un funcionario diferente al juez de conocimiento de la causa. También posee un rasgo inquisitivo el tener como única medida de aseguramiento la detención preventiva que no admitía la libertad provisional, sino excepcionalmente por pena cumplida o por proIongación extrema de la libertad sin haberse calificado el mérito sumarial o realizado la audiencia pública.

La Ley 81 de 1993 igualmente modificó el Decreto 2700 de 1991, consagrando beneficios por colaboración eficaz que permitían al fiscal, previo concepto del procurador, acordar uno o varios beneficios a las personas que sean investigadas, juzgadas o condenadas, en virtud de la colaboración que prestasen a las autoridades de justicia para la desarticulación o mengua de organizaciones delictivas o la captura de uno o varios de sus miembros o la colaboración en la efectiva prevención de delitos o delación de copartícipes, identificación de fuentes de financiación, entrega de bienes, entre otros. Se podía acordar, acumulativamente y en razón del grado de colaboración, la disminución desde la sexta hasta las dos terceras partes de la pena, libertades provisionales, condenas de ejecución condicional, entre otros beneficios.

De igual forma, se consagraron beneficios para personas no vinculadas al proceso penal que rindiesen testimonio o colaborasen con la justicia mediante el suministro de información y pruebas, de no ser sometido a investigación ni acusación por hechos en relación con los cuales rindiese declaración sin incriminarse, cuando su versión o aporte pudiese contribuir eficazmente a la administración de justicia, siempre que no hubiera participado en el delito. Pero si hubiera intervenido en el delito y prestase colaboración, se abriría investigación, pudiéndosele conceder la libertad provisional. 
Estos beneficios son propios de un sistema acusatorio, pero en su momento se consagraron no como un perfil a dicha tendencia, sino como un medio para lograr incrementar los procesos de investigación. Se trataba de impulsar mecanismos de delación ante el crecimiento de este tipo de delincuencia organizada, en especial la del narcotráfico y el secuestro.

La Ley 504 de 1999 creó los jueces penales del circuito especializados con sus respectivos fiscales a partir de su vigencia, es decir, del 1 de julio de 1999. Su competencia cobijaba los delitos más graves contemplados en la legislación penal, como la tortura, homicidio agravado con fines terroristas, lesiones personales con fines terroristas, secuestro extorsivo, fabricación y tráfico de armas y municiones, los delitos señalados en el inciso 1 del artículo 32 de la Ley 30 de 1986, como el lavado de activos, entre otros.

En esta legislación se conservó la protección de la identidad de los funcionarios, pero de manera excepcional, es decir, cuando, previo concepto del Ministerio Publico, atendidas graves circunstancias que pusiesen en peligro la vida o la integridad de los fiscales, podía reservarse la identidad de aquéllos en la etapa de indagación previa y en la instrucción. En todo caso, la audiencia pública durante la etapa del juicio la realiza un fiscal distinto a aquel que realizó la instrucción y cuya identidad se hubiese sometido a reserva.

En relación con la prueba para condenar, se hizo explícito que en los procesos que conociesen los jueces penales de circuito especializados no se podría dictar sentencia condenatoria que tuviese como único fundamento uno o varios testimonios de personas cuya identidad se hubiere reservado. Se mantuvo como única medida de aseguramiento la detención, excluyéndose la detención parcial en el lugar de trabajo o domicilio. Tampoco se podía dictar resolución de acu- sación que tuviese como único fundamento uno o varios testigos de personas cuya identidad se hubiera reservado. Se retornó a la audiencia pública y para su celebración se podían tomar las medidas de seguridad y protección que el juez considerara necesarias. Las normas incluidas en esta ley tienen una vigencia máxima de ocho años.

\section{LEGISLACIÓN PROCESAL PENAL VIGENTE EN ALGUNAS REGIONES DEL PAÍS HASTA EL 2008}

Con la promulgación de la Constitución de 1991, que implicó la adecuación de la normatividad penal a nuevos parámetros contenidos en aquéIla, fue necesario reformar el Código Penal vigente desde 1980. Político-criminalmente era conveniente recopilar toda la legislación penal existente con la finalidad de presentar un proyecto de ley que consignara un Código acorde con el dinamismo social y, de paso, modificar la legislación procesal penal para hacerla más ágil, lo mismo que el régimen penitenciario.

En desarrollo de esta política, la Fiscalía General presentó ante el Senado de la República tres proyectos de leyes por las cuales se expedían los Código Penal (Ley 599 de 2000), de Procedimiento Penal (Ley 600 de 2000) y el Penitenciario que no fue aprobado por el Congreso. Esta nueva legislación comenzó a regir a partir del 24 de julio del 2001, concediéndose un año para su estudio.

Si bien la intención del Fiscal General de la Nación de aquella época era establecer un procedimiento mixto con una clara tendencia acusatoria, no podía hacerlo porque la Constitución no lo permitía. Para ello, era necesario un acto legislativo modificatorio de la Carta que adoptara el nuevo sistema procesal. Por tal razón, las modificaciones no fueron sustanciales, predominando un sistema mixto inquisitivo en la instrucción y acusatorio en el juicio. Veámoslo: 
La Fiscalía continúa realizando la instrucción por medio de sus fiscales delegados. La anterior jurisdicción de orden público y el procedimiento especial para la reserva de identidad se eliminó, pasando la competencia de aquélla a los fiscales especializados, bajo un procedimiento ordinario, cuya vigencia se mantendrá, máximo, hasta el 30 de junio del 2007.

Con la nueva legislación, se trató de agilizar los diferentes procesos penales. En este sentido, se consagró como máximo término de instrucción un año para los eventos en que no exista la necesidad de definir situación jurídica. En los demás casos, el término de instrucción no podrá exceder de 18 meses, contados a partir de la fecha de su iniciación. No obstante, si se tratare de tres o más sindicados o delitos, el término máximo será de 24 meses. La situación jurídica debe ser definida en los eventos en que sea procedente la detención preventiva; y ésta procede, como regla general, cuando el delito tenga prevista pena de prisión cuyo mínimo sea o exceda de cuatro años, o de acuerdo con una lista taxativa en la que se consagran 30 delitos, o cuando en contra del sindicado estuviere vigente sentencia condenatoria ejecutoriada por delito doloso o preterintencional que tenga pena de prisión.

Ahora bien, en los diferentes procesos en los que se tenga que resolver la situación jurídica y cuando ésta se resuelve con detención sin libertad del procesado, se consagra como causal de libertad la siguiente: cuando vencido el término de 120 días de privación efectiva de la libertad, no se hubiere calificado el de instrucción, ampliando el término a 180 días cuando sean tres o más los sindicados contra quienes estuviere vigente detención preventiva. Proferida la resolución de acusación, se revocará la libertad provisional, salvo que proceda causal diferente.
De igual manera, se consagra el control de la medida de aseguramiento y de decisiones relativas a la propiedad, tenencia o custodia de bienes, las cuales podrán ser revisadas en su legalidad formal y material por el correspondiente juez de conocimiento. Para cuestionar la legalidad material, se deberá hacer referencia a la prueba mínima para asegurar en el evento de suponerla o de dejar de valorar una o más pruebas o cuando se demuestre que se distorsionó su contenido; también cuando es practicada o aportada al proceso con desconocimiento de algún requisito condicionante de su validez.

En la legislación vigente se mantienen las dos formas de calificación mediante resolución de acusación o de preclusión de la instrucción. Con la ejecutoria de la resolución de acusación comienza la etapa del juicio. En esta etapa se realiza una audiencia preparatoria en la que se resuelven nulidades y pruebas que deben practicarse en la audiencia pública. Con esta audiencia, se perfila más la tendencia acusatoria en el juicio en la medida que en éste se practicarán las pruebas por parte del juez, pudiendo las partes controvertirlas. Además, se podrá incluir la repetición de aquellas que los sujetos procesales no tuvieron la posibilidad jurídica de controvertir. El juez podrá decretar pruebas de oficio, esto hace que tenga un matiz inquisitivo en la medida en que dicho funcionario funge como juez $y$ como parte.

En esta diligencia de audiencia pública, se ampliaron las posibilidades de contradicción. En ella, el juez interrogará personalmente al sindicado acerca de los hechos, de igual manera podrá escuchar a los funcionarios de Policía Judicial que intervinieron en la investigación. Los sujetos procesales podrán interrogar al sindicado, e inmediatamente se procederá a la práctica de pruebas, de lo cual se dejará constancia en acta, pudiendo utilizarse los medios mecánicos diferentes a la transcripción. 
Era tal el interés de agilizar los procedimientos que se consagró en el inciso final del art. 407 de la Ley 600 de 2000 que antes de dar comienzo a la audiencia el juez acordará con los sujetos procesales el tiempo de intervención de cada uno de ellos, el cual no podrá ser superior en ningún caso a ocho horas. Este inciso fue declarado inexequible por la Corte Constitucional (Sentencia C-760 de julio 18 de 2001, M.P. Marco Gerardo Monroy Cabra). Con esta decisión se resalta la necesidad de propugnar por la oralidad en la audiencia pública y que ella sea un verdadero espacio para la confrontación y contradicción, abandonando como práctica generalizada la presentación de escritos que excusaban al peticionario de hacer una intervención detallada y puntual.

Se agilizaron los mecanismos de terminación anticipada del proceso, manteniendo la figura de la sentencia anticipada, que puede ser solicitada por el sindicado por una sola vez. Si lo es a partir de la diligencia de indagatoria y hasta antes de que quede ejecutoriada la resolución de cierre de investigación, los cargos formulados por el fiscal y aceptados por el procesado se consignarán en un acta suscrita por quienes hayan intervenido y se remitirán las diligencias al juez quien, en el término de diez días hábiles, dictará sentencia de acuerdo con los hechos y circunstancias aceptadas, siempre que no haya habido violación de las garantías fundamentales. El juez dosificará la pena que corresponda y sobre el monto que determine hará una disminución de una tercera parte de ésta.

También se podrá dictar sentencia anticipada cuando, proferida la resolución de acusación y hasta antes de que quede ejecutoriada la providencia que fija fecha para la celebración de audiencia pública, el procesado aceptare la responsabilidad penal respecto de todos los cargos allí formulados. En este caso, la rebaja será de una octava parte.
En el Decreto 2700 de 1991, también se consagró esta forma de terminación anticipada al lado de la audiencia especial del art. 37 a introducida por la Ley 81 de 1993, en la cual el fiscal de oficio o a iniciativa del procesado, directamente o por intermedio de su abogado, puede disponer la celebración de una audiencia especial para presentar los cargos contra el procesado. Con la audiencia se pretendía llegar a un acuerdo respecto a la adecuación típica, grado de participación, las circunstancias del delito, la pena y la condena de ejecución condicional. Terminada la audiencia, se remite al juez de conocimiento, quien profiere sentencia conforme a lo acordado. Este procedimiento fue eliminado en la Ley 600 de 2000 porque tenía inconvenientes que conducían a la dilación del proceso y, en ocasiones, era utilizada buscando alargar la investigación, pues si el juez tenía observaciones acerca de la legalidad del acuerdo, ordenaba devolver el expediente al fiscal, para, posteriormente, citar a una audiencia en la cual aquél y el sindicado discutían las observaciones con el juez y manifestaban si las aceptaban o no, lo cual se consignaba en acta. En caso de aceptar las observaciones, el juez dictaba sentencia. En caso de no aceptar el acuerdo, era improbado mediante auto susceptible de recurso de apelación.

Con miras a la agilización de los procedimientos, la Ley 600 de 2000 logra establecer un procedimiento más expedito en las notificaciones que podrán efectuarse por vía telefónica o en forma virtual. Se pone coto a la tradición de notificación mediante telegramas y oficios que hacía más voluminosa y complicada la labor al obligar dejar constancias de éstos en el expediente.

En este procedimiento mixto, se produce confusión entre labores de instrucción y juzgamiento puro. Es decir, de las funciones propias investigativas y las de índole judicial. En este sentido, en la etapa de instrucción, el fiscal sigue toman- 
do medidas que son del resorte judicial, como ordenar capturas e imponer medida de aseguramiento de detención y medidas de embargo de bienes del sindicado; y el juez, en la etapa de la causa, ordena y practica directamente las pruebas que él incluso oficiosamente puede ordenar. En este sentido, actúa como instructor. En la etapa de instrucción, el juez es un garante indirecto de los derechos y garantías del procesado en relación con la detención o con su captura, mediante los mecanismos de control de legalidad en el primer evento $y$, en el segundo, mediante el recurso del habeas corpus, hoy regulado por la Ley 15 de 1992. En conclusión, los roles no están bien definidos y se encuentran entremezclados.

Por otra parte, el fiscal en la etapa de instrucción no sólo ordena, recauda y practica las pruebas, sino que las valora al momento de tomar medidas de fondo relativas a la detención. En la fase de la instrucción, en la que se agota el período probatorio, se debe perfeccionar la investigación, al punto tal que no se ordenará el cierre hasta tanto no esté concluida, a menos que exista vencimiento de términos, que operan en relación con el proceso en los que el sindicado está detenido. De lo contrario, es común tener procesos con períodos de instrucción de varios años, aunque el Código establezca un término máximo establecido en el art. 329 de la Ley 600 de 2000, de 18 meses contados a partir de la fecha de su iniciación, o máximo de 24 cuando se tratare de tres o más sindicados o delitos. Esta práctica ha demarcado otra de las características del sistema inquisitivo: lento y tedioso.

Otra característica inquisitiva es la no disponibilidad de la acción penal. En la Ley 600, y en todas las legislaciones de procedimiento penal que le anteceden, la acción penal corresponde al Estado y se ejerce por medio de la Fiscalía General de la Nación durante la etapa de la in- vestigación y de los jueces competentes durante la etapa del juzgamiento. Una vez recibida la denuncia o iniciada la investigación oficiosamente, no es posible suspender la actuación judicial argumentando conveniencias de índole políticocriminal y no en aspectos dogmáticos o causales objetivas que impidan continuar con la investigación la cual conduce a la preclusión de la misma. Sólo es posible, a través de mecanismos como el desistimiento, la conciliación y la preclusión por las causas establecidas taxativamente en la ley procesal, o la preclusión en el evento de la indemnización integral, cuando el delito por el cual se procede permite la preclusión por reparación integral.

En conclusión, el sistema procesal de la Ley 600 de 2000 configura un sistema procesal mixto, con rezagos inquisitivos, pero con una marcada tendencia acusatoria. Veámoslo:

Resulta ser mixto por la demarcación clara de dos etapas, cada una con su director. Éste, sin duda, fue el aporte más importante del sistema mixto. Pero, al mismo tiempo, posee rasgos inquisitivos manifiestos: considerar la investigación como oficiosa, excepto cuando la acción tiene su origen en la querella; facultades del juez para investigar en el juicio; procedimiento escrito en la instrucción; intervención de la sociedad a través del Ministerio Público; y el fiscal no puede disponer del proceso.

La tendencia acusatoria se expresa por: separación de las funciones de acusar y juzgar; no incomunicación del sindicado; libre apreciación de las pruebas por el juez; posibilidad de los sujetos procesales de controvertir las pruebas; control de legalidad en las medidas de aseguramiento; la inmediación del juez en las pruebas practicadas en el juicio; la oralidad; mecanismos de sentencia anticipada; agilidad en los procedimientos de notificación; ampliación de delitos en los que procede el desistimiento, la conciliación y la indemnización integral que no está limitada a cuantía. 


\section{LEGISLACIÓN PROCESAL PENAL ACUSATORIA A PARTIR DEL 1 DE ENERO DE 2005}

Al tratarse de una legislación procesal nueva, que implica cambios de índole administrativo y cultural, se hizo necesario su implantación gradual y sucesiva. Para ello, se tuvieron en cuenta algunos criterios que cobijan los factores referidos al número de despachos y procesos en la Fiscalía y en los juzgados penales, el registro de servidores capacitados en oralidad, proyección sobre el número de las salas de audiencias, la demanda en justicia penal y requerimientos de la defensoría pública, el nivel de congestión y las reglas de gradualidad fijadas en la misma Ley 229 de 2004.

Así, se determinó que el nuevo sistema procesal penal se aplicará a partir del 1 de enero de 2005 en los distritos judiciales del Eje Cafetero (Armenia, Manizales y Pereira) y en Bogotá, en una primera fase. En la segunda etapa, a partir del 1 de enero de 2006, se incluirá a los distritos judiciales de Bucaramanga, Buga, Cali, Medellín, San Gil, Santa Rosa de Viterbo y Tunja. El 1 de enero de 2007, entrarán al nuevo sistema los distritos judiciales de Antioquia, Cundinamarca, Florencia, Ibagué, Neiva, Pasto, Popayán y Villavicencio. Por último, el 1 de enero de 2008, se aplicará en los distritos judiciales de Barranquilla, Cartagena, Cúcuta, Montería, Quibdó, Pamplona, Riohacha, Santa Marta, Sincelejo y Valledupar. En los que se creen con posterioridad, entrará a aplicar el sistema a partir del 1 de enero de 2008.

Este sistema procesal conlleva, además, unos ajustes administrativos relacionados con la planta de personal de la Fiscalía General de la Nación, la Rama Judicial y de las entidades que cumplen funciones de policía judicial, con el fin de conseguir la transición hacia el sistema acusatorio previsto en el Acto Legislativo 03 de 2002. El término para la reubicación de los funcionarios será de dos años y la legislación procesal acusatoria comenzará a regir para los delitos cometidos con posterioridad al 1 de enero del año 2005, exceptuando los procesos de investigación y juzgamiento a los miembros del Congreso que se regirán por la Ley 600 de 2000.

De acuerdo con el art. 2 del Acto Legislativo 03 de 2002, que modifica el art. 250 de la Constitución Nacional, la Fiscalía General de la Nación, adelanta el ejercicio de la acción penal a través de la investigación de los hechos presuntamente constitutivos de delito que conozca por denuncia, petición especial, querella o de oficio; además, está obligada a realizar la investigación de los hechos que revistan las características de un delito, razón por la cual no podrá suspender, interrumpir ni renunciar a la persecución penal, salvo en los casos que establezca la ley para la aplicación del principio de oportunidad, regulado dentro del marco de la política criminal del Estado, el cual estará sometido al control de legalidad por parte del juez que ejerza las funciones de control de garantías.

En este contexto, la regla en materia de investigación y acusación la determina el principio de legalidad; y la excepción será el principio procesal de la oportunidad, según el cual se faculta a la Fiscalía, en casos expresamente determinados en el Código de Procedimiento Penal, para optar entre investigar o dejar de hacerlo, acusar o precluir, de acuerdo con conveniencias políticocriminales, así la prueba conduzca a la existencia de la conducta punible y a la responsabilidad del imputado, pero con el requisito adicional de que esa decisión sólo se consuma con el aval del juez que ejerce la función de control de garantías.

El principio de oportunidad, que al ser reglado es más una excepción que un principio, es la facultad que tiene la Fiscalía General de la Nación para abstenerse de ejercer la persecución 
penal, suspenderla o renunciar a ella en los casos establecidos en la ley procesal penal, específicamente en la Ley 906 de 2004, cuya aplicación sólo será posible antes de presentarse la acusación.

Esta posibilidad se consagra si se presentan causales sustanciales, como cuando la antijuridicidad material en los delitos cuyo injusto sea susceptible de graduación pierda entidad jurídica dadas las condiciones del titular del bien jurídicamente tutelado, muy a pesar de haberse descartado la insignificancia; también cuando no sea posible reconocer la relevancia excusante de una causal de atipicidad por verificarse un exceso en su ejercicio, pero que ante un juicio global de normalidad social de la situación la misma no amerita una reacción penal, entre muchos otros señalados taxativamente.

Así pues, para una regulación equilibrada del principio de oportunidad se han tenido en cuenta, según la exposición de motivos de la Ley, elementos como la readecuación social del hecho, la ínfima importancia, la culpabilidad disminuida, la retribución natural (pérdida de un hijo con el que se tiene relación de afecto actual en un siniestro provocado por culpa del imputado) o la reevaluación del interés público en la persecución de la conducta; además de la posibilidad de prescindir de la persecución en un hecho de menor importancia para aplicar los mayores esfuerzos a otros más graves, o la posibilidad de suspender la persecución de una conducta, o parte de ella, para orientarse a otra más grave y la posibilidad de suspender el proceso o la pena para someter a prueba al imputado o acusado.

Otra de las razones para instaurar el principio de oportunidad hace referencia a un factor de costo-beneficio. En casos insignificantes, es mayor el costo que conlleva el proceso penal, el desgaste de la administración de justicia, que el beneficio que se obtiene con la condena. Es tal la congestión que causan procesos penales de menor gravedad, por llamarlos de algún modo, que lo único que logran es abrumar a tal punto la administración de justicia que la hace inoperante e ineficiente para otros asuntos de mayor gravedad, que se quedan relegados y postergados por el recargo de trabajo ocasionado por los procesos menores.

Sin duda, se afirmó en el Proyecto, escasean los medios personales y materiales para perseguir la criminalidad, pero tal deficiencia se ve agravada por la falta de realismo del legislador. Al legislador le resulta más fácil y, sobre todo, más barato, tipificar determinadas conductas como delito y aumentar las penas, en cambio de adoptar medidas eficaces de política social. Pretender que la desviación social puede combatirse únicamente mediante nuevas leyes de creación de delitos y aumento de penas conduce a una sobrecriminalización.

Es precisamente en este principio de oportunidad que el sistema acusatorio propuesto adquiere mayor relevancia porque la estricta legalidad no debe ser el criterio imperante, así exista todo el material probatorio necesario, incluso, para formular una acusación y soportar una sentencia condenatoria, pues este principio debe ceder ante postulados político-criminales que hacen innecesario desgastar el sistema judicial frente a conductas punibles, que por sus particulares circunstancias no conllevaría al merecimiento de pena.

Consideramos que la legislación procesal acusatoria aprobada se muestra acorde y en armonía con los principios que rigen las sanciones penales consagrados en el art. 3 del Código Penal, en el que se establece la necesidad, proporcionalidad y razonabilidad. En este contexto, la legislación procesal acusatoria agiliza y permite viabilizar el principio de necesidad de pena; es una forma de anticipar la facultad discrecional que tiene el juez de conocimiento, evitando 
adelantar todo en proceso penal y cuyo resultado terminará en la abstención de imponer una sanción penal por innecesaria.

En la exposición de motivos del proyecto legal, se indicaba que a partir de la consagración constitucional y legal del principio de oportunidad no se trata de abrir posibilidades incontroladas para que el fiscal deje de investigar o de acusar a su talante, motivado tal vez por intereses particulares ajenos a la política criminal del Estado, sino de entender que cada conducta delictiva y cada imputado pueden presentar rasgos específicos, cuya complejidad psíquica y social exige una valoración, que no puede hacerse mediante una mera interpretación y aplicación de las correspondientes normas jurídicas. Por ello, una respuesta proporcionada a las características de cada caso requeriría un cierto margen de discrecionalidad que obra a favor de la comunidad y de los ciudadanos y no propiamente de quien ostenta el poder punitivo.

En este contexto, es trascendental enmarcar la figura dentro de un plano de política criminal. El proceso penal busca la efectividad de la justicia a tal punto que puede prescindir de su labor investigativa para dar paso a la materialización de la justicia. El proceso penal no queda circunscrito a la labor probatoria respecto a la existencia de la conducta punible y la responsabilidad del procesado, sino que debe extenderse a una visión dentro del marco de la necesidad de la sanción penal, e incluso de la iniciación del proceso penal.

La esencia del proceso penal deja de ser el conjunto de acciones para determinar si el acusado es responsable o no, dentro del marco de la mera y estricta legalidad, para dar cabida a principios que priman, como el de la dignidad humana, que es el pilar fundamental en el Estado social y democrático de derecho. Se constituye en una injusticia y un desgaste a la administración de justicia adelantar un proceso penal, con los costos sociales, económicos, culturales e ideológicos cuando la conducta punible es de ínfima importancia, o cuando está reducida su culpabilidad o su antijuridicidad material, entre otras de las causales de improcedencia de la acción penal, diferentes a las objetivas, como la prescripción, la caducidad o la ausencia de querella.

El principio de oportunidad se erige entonces en el primero de los principios sustanciales que rigen el sistema procesal acusatorio y que, al lado de la inmediación y contradicción en la práctica de pruebas, estructura un sistema que permite, en el evento de una acusación, que ésta no sólo sea sustentada, sino, además, controvertida y vencedora en un juicio para poder sobre ella fundamentar un fallo de carácter condenatorio.

En el régimen acusatorio que empezó a regir se lleva a rango constitucional, a través de la norma rectora, el principio de la inmediación, principio que ordena que la prueba debe ser practicada en presencia del juez que va a decidir respecto a la acusación que formuló la Fiscalía como ente acusador. Sólo se exceptúa el principio en relación con la prueba de referencia y la prueba anticipada; por ello, el legislador fue tan meticuloso en indicar qué es la prueba de referencia y en qué casos específicos procede, obviamente siendo ella de carácter excepcional.

En el juicio oral únicamente se estimará como prueba la que haya sido producida o incorporada en forma pública, oral, concentrada, sujeta a confrontación y contradicción ante el juez de conocimiento. De ahí que en el sistema acusatorio se torna vital el principio de oralidad que permite una mayor confrontación y controversia de las pruebas, toda vez que se practican en presencia de las partes, de los intervinientes y del juez. Así entonces, se permite una mayor inmediatez en su confrontación y apreciación de las pruebas. 
Otros dos principios acompañan al sistema acusatorio en relación con la prueba, ellos son el de concentración y la cláusula de exclusión. El primero de ellos hace referencia a que, durante la actuación procesal, la práctica de pruebas y el debate deberán realizarse de manera continua, con preferencia en un mismo día; ese debate se hace en la diligencia de audiencia pública en el juicio oral, de ahí que este principio esté íntimamente relacionado con la oralidad para evitar que se disperse la práctica de pruebas como en su debate, discusión y apreciación. El segundo implica que toda prueba obtenida con violación de las garantías fundamentales será nula de pleno derecho, por lo cual deberá excluirse de la actuación procesal.

Lo trascendental entonces en el sistema acusatorio es que se permita la controversia, que las pruebas se alleguen de manera pública y oral para permitir el debate y la confrontación de la partes en igualdad de condiciones. En el sistema acusatorio se destaca la oralidad como principio rector del procedimiento, que significa que el proceso se adelanta de manera verbal en audiencias públicas, aboliéndose la utilización de procedimientos escritos, aunque se consagra la posibilidad de utilizar recursos técnicos para guardar el archivo de lo acontecido en el juicio.

De igual manera, se establece que las decisiones judiciales se adopten oralmente en la misma audiencia, quedando notificadas las partes en estrados. Acorde con la práctica acusatoria que realza la posición del juez como supremo director del proceso, se le otorgan amplias facultades para conducir la actuación (limitar la intervención de los sujetos procesales de manera proporcional y razonable en relación con el objeto procesal materia de debate) y disciplinarias.

La Fiscalía, en cumplimiento de sus funciones como titular de la acción penal, tiene atribuciones específicas que le permiten investigar y acu- sar a los presuntos responsables de haber cometido un delito, aplicando el principio de oportunidad, ordenando, si fuere necesario, registros, allanamientos, interceptaciones, que debe poner a disposición del juez de garantías; también está obligada a: asegurar los elementos probatorios garantizando su cadena de custodia mientras se ejercen su contradicción; dirigir las funciones de policía judicial que ejercen los organismos de investigación, protegiendo a las víctimas, los testigos y demás intervinientes, ordenando capturas de manera excepcional, poniendo la persona a disposición del juez de garantías; y solicitar a éste las medidas necesarias que aseguren la comparecencia de los imputados, la conservación de la prueba y la protección de la comunidad.

La Fiscalía debe actuar de acuerdo con el principio de objetividad que le exige adecuar su actuación a un criterio objetivo y transparente. En este sentido, podrá presentar la acusación ante el juez de conocimiento para dar inicio al juicio oral o solicitar ante el juez de conocimiento la preclusión de las investigaciones, cuando no hubiere mérito para acusar.

La Policía Judicial siempre actuará bajo la dirección y coordinación de la Fiscalía, para lo cual deberán acatar las instrucciones impartidas por el Fiscal en cada caso concreto. La omisión acarreará sanciones; por ello, el fiscal deberá separar de forma inmediata de las funciones al funcionario que omitió o se extralimitó en el cumplimiento de las instrucciones.

La defensa tendrá atribuciones para asistir personalmente al imputado desde su captura; disponer de tiempo y medios razonables para la preparación de la defensa; conocer en el evento de una acusación todos los elementos probatorios que tenga la Fiscalía, incluidos los que sean favorables al procesado; controvertir las pruebas así se trate de pruebas anticipadas; interrogar y 
contrainterrogar en el juicio oral a los testigos y peritos; solicitar al juez la comparecencia de testigos y peritos; interponer recursos; solicitar nulidades; no ser obligado a presentar prueba de descargo o contraprueba ni a intervenir activamente durante el juicio oral.

El Ministerio Público tendrá una participación contingente. En virtud de ella, podrá, como garante de los derechos humanos y de los derechos fundamentales, ejercer vigilancia sobre las actuaciones de la Policía Judicial; participar en las diligencias realizadas por la Fiscalía y los jueces; procurar que las decisiones judiciales cumplan con los cometidos de lograr la verdad y la justicia; procurar que la privación de la libertad se cumpla dignamente; abrogar porque se defina rápidamente la competencia entre diferentes jurisdicciones en procesos por graves violaciones a los Derechos Humanos y al Derecho Internacional Humanitario; $y$ velar por el cumplimiento del debido proceso y el derecho de defensa.

El Ministerio Público, en representación de la sociedad, podrá: solicitar la condena o absolución de los acusados e intervenir en la audiencia de control judicial de la preclusión de la investigación; procurar la indemnización de perjuicios; el restablecimiento del derecho; solicitar las pruebas que a ello conduzcan y las medidas cautelares que procedan; velar porque se respeten los derechos de las víctimas, testigos, jurados y demás intervinientes.

A quien demuestre su calidad de víctima, el fiscal garantizará que se le informe sobre el trámite dado a su denuncia o querella; permitirle seguir el desarrollo de la investigación; posibilidad de dar aplicación al principio de oportunidad y a ser escuchada tanto por la Fiscalía como por el juez de control de garantías; la fecha y el lugar del juicio oral; la fecha de audiencia de dosificación de la pena; la sentencia del juez y el derecho a promover el incidente de reparación integral. Y en caso de que exista riesgo para la víctimas, se le informará sobre la puesta en libertad de la persona inculpada.

Las víctimas en garantía de sus derechos podrán solicitar al fiscal medidas de protección; el interrogatorio a ellas debe realizarse con respeto. Para el ejercicio de sus derechos no es necesario que estén representadas por abogado, esto sólo es imperativo a partir de la audiencia preparatoria. Ahora bien, el juez podrá excepcionalmente, con la finalidad de proteger a las víctimas, decretar que durante su intervención el juicio se celebre a puerta cerrada. Las víctimas podrán formular ante el juez de conocimiento el incidente de reparación íntegra, una vez establecida la responsabilidad penal del imputado.

El juez de conocimiento, durante toda la actuación, debe ser imparcial y, con base en las pruebas practicadas en su presencia, a excepción de las anticipadas, controvertidas de manera pública, oral y concentrada, debe evaluar la responsabilidad del acusado y dictaminar sobre ella mediante su fallo. En su presencia, se presentan, por parte de la Fiscalía, la cual ejerce la acción penal, las pruebas de cargo adecuadas para desvirtuar la presunción de inocencia. La defensa también presenta las pruebas de descargo si las tiene y controvierte las presentadas.

En el esquema procesal diseñado para el nuevo procedimiento penal se procura la igualdad de derechos y oportunidades de los sujetos procesales. Por ello, se contempló la existencia de un estadio previo a la acusación llamado formulación de la imputación, con el cual se comunica en audiencia, ante el juez de control de garantías, su condición de imputado y se le informa que existe una investigación en su contra, para que él, con su abogado, pueda comenzar a ejercer su derecho de defensa. 
El carácter de sujeto procesal imputado se adquiere desde la vinculación a la actuación mediante captura, si ésta ocurriere primero o desde la formulación de la imputación. A partir de la presentación de la acusación, adquiriá la condición de acusado.

Cuando el fiscal no haya podido lograr la comparecencia de una persona, y la requiera para formularle imputación o tomar alguna medida de aseguramiento en su contra, solicitará ante el juez de control de garantías que lo declare persona ausente.

Además de los derechos reconocidos en los Tratados Internacionales de Derechos Humanos ratificados por Colombia y que forman parte del "bloque de constitucionalidad" de la Constitución Política y de la ley, el imputado o procesado, según el caso, dispondrá de las mismas atribuciones asignadas a la defensa que resulten compatibles con su condición. En todo caso, de mediar conflicto entre las peticiones o actuaciones de la defensa con las del imputado o procesado, prevalecen las de aquélla.

Con el procedimiento acusatorio, se ha pretendido darle agilidad a las actuaciones y procesos penales. Así, en el art. 175 de la Ley 906 de 2004 estable los siguientes términos:

- El término de que dispone la Fiscalía para formular la acusación, solicitar la preclusión o aplicar el principio de oportunidad no podrá exceder de treinta (30) días contados desde el día siguiente a la formulación de la imputación.

- La audiencia preparatoria la deberá realizar el juez de conocimiento a más tardar dentro de los treinta (30) días siguientes a la audiencia de formulación de acusación.

- La audiencia del juicio oral tendrá lugar dentro de los quince (15) días siguientes a la conclusión de la audiencia preparatoria.
De otra parte, en el proceso acusatorio se le confiere mayor importancia a las labores y actividades de la Policía Judicial, que serán desarrolladas por los organismos que cumplen este papel, pero bajo la coordinación del fiscal, a quien corresponde la carga de la prueba y, por lo tanto, quien debe indagar e investigar los hechos delictivos que lleguen a su conocimiento mediante denuncia, querella, petición especial o por cualquier otro medio idóneo.

En desarrollo de la función prevista, le corresponde a la Fiscalía General de la Nación la coordinación, control jurídico y verificación técnicocientífica de las actividades que desarrolle la Policía Judicial. En desarrollo de lo anterior, los servidores públicos que, en ejercicio de sus funciones de policía judicial, reciban denuncias, querellas o informes de cualquier clase, de los cuales se infiera la posible comisión de un delito, realizarán de inmediato todos los actos urgentes, tales como inspección en el lugar del hecho, levantamiento de cadáver, entrevistas e interrogatorios. Además, identificarán, recogerán, embalarán técnicamente los diferentes elementos materiales probatorios y registrarán por escrito, grabación magnetofónica o fonóptica, las entrevistas e interrogatorios, y los someterán a cadena de custodia.

Del inicio de la indagación se presentará un informe ejecutivo al fiscal competente. Cuando la Policía Judicial, en desarrollo de su actividad, considere fundadamente que una persona fue víctima o testigo presencial de un delito o que tiene alguna información útil para la indagación o investigación que se adelanta, realizará entrevista con ella. La entrevista se efectuará observando las reglas técnicas pertinentes y se emplearán los medios idóneos para registrar los resultados del acto investigativo. Sin perjuicio de lo anterior, el investigador deberá, al menos, dejar constancia de sus observaciones en el cuaderno de notas, en relación con el resultado de la entrevista. 
El fiscal, recibido el informe de la Policía Judicial, si fuere el caso, procederá a la ratificación del mismo, creando un equipo con el cual trabajará durante toda la investigación para llegar a sustentar la acusación en el evento en que sea procedente ante el juez del conocimiento en un juicio oral y contradictorio. La importancia del énfasis que se le ha dado en el sistema acusatorio al trabajo en equipo entre el fiscal y la Policía Judicial depende de que ambos deben trazarse un plan metodológico investigativo que contendrá la hipótesis delictiva, los criterios para evaluar la información, la delimitación de las tareas y órdenes de trabajo, el cronograma y los procedimientos de control y verificación.

En desarrollo del programa metodológico de la investigación, el fiscal ordenará la realización de todas las actividades que no impliquen restricción a los derechos fundamentales y que sean conducentes al esclarecimiento de los hechos, al descubrimiento de los elementos materiales probatorios, a la individualización de los autores y partícipes del delito, a la evaluación y cuantificación de los daños causados y a la asistencia y protección de las víctimas.

El fiscal o el servidor de Policía Judicial también podrá interrogar al indiciado. Si tuviere motivos fundados para inferir que una persona es autora o partícipe de la conducta que se investiga, sin hacerle imputación alguna, podrá interrogarlo acerca de sus datos personales. Si el interrogado aceptare espontáneamente ser autor o partícipe, de inmediato le hará saber que no está obligado a declarar contra sí mismo y que tiene derecho a designar un defensor. Antes de proseguir el interrogatorio, el indiciado deberá estar asistido por su defensor.

En todo caso, las actividades de investigación de campo, de estudio y análisis de laboratorio serán realizadas directamente por la Policía Judicial.
Examinado el informe de inicio de las labores realizadas por la Policía Judicial y analizados los primeros hallazgos, si resultare que han sido diligenciadas con desconocimiento de los principios rectores y garantías procesales, el fiscal ordenará el rechazo de la indagación e informará de las irregularidades advertidas a los funcionarios competentes en los ámbitos disciplinario y penal.

Precisamente en este punto consideramos que puede llegarse a desequilibrar la balanza de igualdad de los sujetos procesales, toda vez que la defensa no contaría con las mismas posibilidades en actos de investigación de campo y de estudio de laboratorio. Así se verían reducidas las posibilidades de búsqueda de pruebas de descargo a través de entrevistas, seguimientos, búsqueda de testigos, todo lo cual requiere de un equipo técnico e investigativo, como ocurre con la Fiscalía que cuenta para ello con la Policía Judicial.

Aún más, la defensa no podría contar con la posibilidad de creación de grupos especiales como lo hace la Fiscalía, cuando por la complejidad de la investigación acude a la conformación de unidades especiales integradas por fiscales y miembros de Policía Judicial que se requieran.

Aunque los arts. 8 y 125 de la Ley 906 de 2004 consagran explícitamente las facultades de la defensa en la investigación, consideramos que, aún así, ellas no son suficientes para lograr un verdadero y estricto equilibrio de los sujetos procesales. Para ello, se requeriría la creación de grupos de abogados defensores que trabajaran en equipo (bufetes) y que contaran con entidades de investigación privadas que les sirvieran de apoyo. Sin duda, esto seguramente va a ocurrir en el nuevo sistema procesal, pero esto encarecerá la defensa de las personas y hará todavía más inaccesible el acceso a la justicia penal y a un juicio justo para los más pobres. 
En el nuevo sistema acusatorio, se establece que quien advierta que la Fiscalía adelanta investigación en su contra podrá asesorarse de un abogado. Aquél o éste podrá buscar, identificar empíricamente, recoger y embalar los elementos materiales probatorios y hacerlos examinar por peritos particulares a su costa; tales elementos y el informe sobre ellos pueden ser utilizados en su defensa ante las autoridades judiciales. También podrá entrevistar personas con el fin de allegar información útil que pueda ser empleada en su defensa, siempre que se garantice la cadena de custodia.

Además, el imputado o su defensor, durante la investigación, podrá buscar, identificar empíricamente, recoger y embalar elementos materiales probatorios. Con la solicitud para que sean examinados y la constancia de la Fiscalía de que se es imputado o defensor de éste, serán trasladados al respectivo laboratorio del Instituto $\mathrm{Na}$ cional de Medicina Legal y Ciencias Forenses.

De igual manera, se indica que el imputado o su defensor podrá entrevistar a personas con el fin de encontrar información útil para la defensa. En esta entrevista se emplearán las técnicas aconsejadas por la criminalística. La entrevista se podrá recoger y conservar por escrito, en grabación magnetofónica, en video o en cualquier otro medio técnico idóneo.

Para obtener declaración jurada, el imputado o su defensor podrá solicitar a un alcalde municipal, inspector de policía o notario público que le reciba declaración jurada a la persona, cuya declaración pueda resultar de especial utilidad para la investigación. Ésta podrá recogerse por escrito, grabación magnetofónica, en video o en cualquier otro medio técnico idóneo.

También el imputado o su defensor podrá solicitar al juez de control de garantías la práctica anticipada de cualquier medio de prueba, en casos de extrema necesidad y urgencia, para evitar, de esta manera, la pérdida o alteración del medio probatorio. Se efectuará una audiencia, previa citación al fiscal correspondiente para garantizar el contradictorio. Se aplicarán las mismas reglas previstas para la práctica de la prueba anticipada y cadena de custodia.

En el art. 308 de la Ley 906 de 2004 se establece la prueba necesaria para solicitar medida que asegure la comparecencia del imputado al proceso penal, indicando que para dictar medida que asegure la comparecencia del imputado al proceso penal es suficiente que de los elementos materiales probatorios o de la información legalmente obtenida se pueda inferir razonablemente que el imputado es autor o partícipe de la conducta delictiva que se investiga. Además, que la medida de aseguramiento se muestre como necesaria para evitar que el imputado obstruya el debido ejercicio de la justicia; que el imputado constituye un peligro para la seguridad de la sociedad o de la víctima; y que resulte probable que el imputado no comparecerá al proceso o que no cumplirá la sentencia.

Que sea razonable conlleva no sólo que la prueba debe respetar los principios y las garantías consagradas en la Constitución y la ley, impidiendo que se practiquen pruebas ilegales o violatorias de derechos fundamentales que, por aplicación de la cláusula de exclusión, será nula de pleno derecho, sino que también hace referencia a la inferencia que el imputado es autor o partícipe de la conducta delictiva que se investiga.

En el sistema acusatorio que debe implantarse en forma gradual en el período 2005-2008, se establecen como medidas de aseguramiento privativas de la libertad, la detención preventiva y la detención domiciliaria. No privativas de la libertad: la obligación de someterse a vigilancia electrónica o de una persona o de una institución; la obligación de presentarse periódicamen- 
te; la obligación de observar buena conducta individual, familiar y social; la prohibición de salir del país; la prohibición de concurrir a determinadas reuniones o lugares, la prohibición de comunicarse con determinadas personas o con las víctimas; la prestación de una caución y la prohibición de salir del lugar de habitación.

El fiscal solicitará al juez de control de garantías imponer medida de aseguramiento, indicando la persona, el delito, los medios cognoscitivos que pretende hacer valer y la urgencia de la misma, los cuales se evaluarán en audiencia permitiendo a la defensa la controversia pertinente. Escuchados los argumentos del fiscal, del Ministerio Público y de la defensa, el juez emitirá su decisión. La presencia del defensor constituye requisito de validez de la respectiva audiencia. Frente a esta decisión proceden recursos.

Para elaborar el escrito de acusación, es suficiente que de los elementos materiales probatorios 0 de la información legalmente obtenida se pueda afirmar, con probabilidad de verdad, que la conducta delictiva existió y que el imputado es su autor o partícipe.

A partir de la presentación de la acusación, adquirirá el imputado la condición de acusado y, para ello, se requerirá una exigencia probatoria mayor en el sentido de que se pueda afirmar, con probabilidad de verdad, que la conducta delictiva existió y que el imputado es su autor o partícipe. Es más, se requiere, a nuestro juicio, que la Fiscalía haya desvirtuado la presunción de inocencia, porque de lo contrario solicitará ante el juez de conocimiento preclusión de la investigación. En este sentido, se presentará escrito de acusación cuando la Fiscalía tiene pleno convencimiento de la responsabilidad del acusado; pero de no existir tal exigencia probatoria, deberá aplicarse el principio de in dubio pro reo.
La naturaleza del proceso acusatorio se afirmaba en la presentación de motivos del Proyecto de la Ley Procesal, que al estar regido prioritariamente por los principios de inmediación y concentración, la acción penal comienza a ejercerse a partir de la formulación de la imputación, momento a partir del cual se interrumpe la prescripción de la acción penal. En ella, la Fiscalía no tiene la obligación de revelar los elementos materiales probatorios que haya recolectado, puesto que aquéllos sólo serán dados a conocer a partir de la presentación de la acusación, cerrándose así las puertas para que la formulación de la imputación se convierta en un escenario sumarial o anticipación del juicio. En la audiencia de lectura de acusación, se cumpliá lo relacionado con el descubrimiento de la prueba.

Lo anterior es coherente con el propio sistema acusatorio que difiere del inquisitivo en el sentido que en el ente acusador recae la carga de la prueba y la necesidad de desvirtuar el principio de inocencia, y para poder formular una acusación debe tenerse una base probatoria que de por sí desvirtúa, en criterio del ente acusador, dicha presunción, pues, de lo contrario, deberá el fiscal solicitar la preclusión como consecuencia precisamente de la imposibilidad de desvirtuar dicho principio, según lo establece el numeral 6 del art. 332 de la Ley 906 de 2004.

En Colombia, con la nueva legislación procesal acusatoria, se pretende un código enmarcado dentro de una política criminal de mínima intervención, protectora de las garantías fundamentales, con un principio de oportunidad reglado. Se ha estructurado una normatividad equilibrada para los intervinientes en el proceso penal, fuerte en su acusación, con posibilidades de defensa en la contradicción, con la participación del Ministerio Público en interés de la sociedad y en la cual se recupera la categoría cultural del juez. 
Sin embargo, existen algunos puntos de controversia que sólo enunciaremos porque requerirán de una confrontación posterior con la entrada en vigencia de la nueva legislación procesal penal. Veámoslos a manera de conclusión:

Como decíamos, no existe equilibrio entre las partes porque el fiscal tiene todo el tiempo para indagar, antes que le prescriba la acción, mientras que la defensa tiene como máximo 30 días para preparar la defensa. Aunque puede ser menor, porque los términos para la instrucción son máximos no mínimos; por lo tanto, un fiscal puede formular una imputación en los términos expuestos por la Ley 906 de 2004 y presentar el escrito de acusación al día siguiente.

Es un sofisma hablar que no existe proceso penal, sino indagación preprocesal, cuando se priva de la libertad al indiciado o imputado, según el caso. Igualmente, es un sofisma afirmar que el fiscal no toma decisiones judiciales porque ahora no emite órdenes de captura ni medidas de aseguramiento. Pero, ¿ordenar seguimientos, registros, vigilancias, interceptaciones, incluso presentar un escrito de acusación, no son decisiones judiciales?

La defensa privada no tiene los medios organizativos para estructurar la consecución de medios probatorios a favor de su cliente. Se deberá apoyar en investigadores privados o crear equipo de trabajo con varios profesionales en las diversas áreas del conocimiento. Ahora bien, la defensa pública está en desventaja frente a la Fiscalía en cuanto a la colaboración de los funcionarios de Policía Judicial que actúan bajo su dirección.

Un aspecto inquietante es que la Policía Judicial puede llegar a limitar los derechos del indiciado, sin existir en su contra una imputación fáctica y jurídica de haber cometido un delito. En tal sentido, se podrán hacer seguimientos, vigilancias, registros inclusive, sin previa formalización de la imputación, incluso para esta última el término para ejecutar la orden de registro es inferior a cuando se ordena posterior a la imputación, según lo establecido en el art. 224 de la Ley 906 de 2004.

No se establecen términos perentorios para formular la imputación cuando la persona ha sido capturada. Un vacío que indica que una persona al ser capturada debe ser puesta en el término de 36 horas a disposición del juez de garantías para el control posterior de la aprehensión $y$, en esa misma diligencia, creemos que la Fiscalía debe hacer la imputación y, de ser procedente, solicitar la medida de aseguramiento que corresponda. Todo esto en aras de garantizar la legitimidad de la privación de la libertad.

En caso de no ser capturado, el fiscal puede hacer la imputación y no solicitar medida de aseguramiento porque no existe su urgencia, por ejemplo. En dicho evento, se presentará el escrito de acusación que deberá afirmar, con probabilidad de verdad, que la conducta delictiva existió y que el imputado es su autor o partícipe. En estos eventos, la controversia se traba desde el momento en que se presenta el escrito de acusación por parte de la Fiscalía General de la Nación, no antes, porque la imputación que se le hiciera tiene un carácter meramente informativo de los cargos y de los derechos que se tiene como imputado. El problema es que sólo se tienen a lo sumo tres días para preparar la defensa, término dentro del cual se citará para audiencia de formulación de la acusación y, en ella, se dará inicio al descubrimiento de prueba que realiza la Fiscalía fijando la fecha para la audiencia preparatoria, que deberá realizarse en un término no inferior de 15 días ni superior a 30. Es decir, la defensa contaría a lo sumo con un mes para buscar los medios de prueba que se solicitarán practicar en el juicio oral. 
Ahora bien, si la persona es capturada, se le hará la imputación en la misma diligencia de control posterior a la aprehensión y en ella podrá la Fiscalía solicitar la medida de aseguramiento, cuando es procedente y necesaria la privación de la libertad. Una vez esto ocurra, se tiene con un término máximo de 30 días o, excepcionalmente, 60 días, cuando el fiscal no ha presentado el escrito de acusación, para preparar la defensa. La legislación indica que no podrá exceder de 30 días; por lo tanto, un fiscal puede, una vez obtenida la legalización de la captura, al día siguiente, presentar el escrito de acusación. En este evento, se tendría a lo sumo un mes para buscar los medios de prueba por parte de la defensa.

No existe equilibrio en el juicio porque en él la defensa se enfrenta a la acusación de la Fiscalía, a la solicitud de condena del representante de la víctima y, en la mayoría de los casos, al concepto del Ministerio Público que en pocas ocasiones, en la práctica, difiere del fiscal.
Emitir el sentido del fallo en tan solo dos horas puede llevar a que el juez, al redactar la sentencia conforme al enunciado de su fallo, entre en una confusión que podría ser meditada con calma y de manera razonable. Cuántas veces al comenzar a emitir un fallo se piensa que va a ser absolutorio, pero al detallar cada prueba puede cambiar de posición y termina siendo condenatorio, o cuántas veces no ha sucedido a la inversa, comienza con la idea de condenar pero, al momento de valorar todas y cada una de las pruebas, se llega a la conclusión de que existen dudas que no permiten obtener la prueba necesaria para condenar, es decir la certeza. ¿Qué camino tomaría el juez que una vez emitido el sentido del fallo en sentido condenatorio $y$, al redactar la sentencia, encuentra que no existe mérito para condenar? o, en caso contrario, ¿si emitió fallo absolutorio $y$, al redactar la sentencia, encuentra que si existe mérito para condenar? ¿Qué sucede si, además, ningún sujeto procesal interpone recurso contra la sentencia? 